DOI: 10.4274/jarem.galenos.2019.2577

J Acad Res Med 2020; 10(1): 70-4

\title{
The Comparison of the Management Models for Identifying the Risk of Serious Bacterial Infection in Newborn Infants with a Newly Developed Scale
}

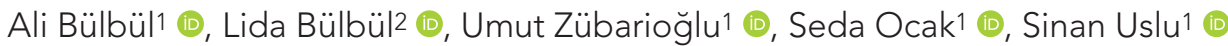 \\ ${ }^{1}$ University of Health Sciences Turkey, İstanbul Şişli Hamidiye Etfal Training and Research Hospital, Clinic of Pediatrics, Division of \\ Neonatology, İstanbul, Turkey \\ 2University of Health Sciences Turkey, Bakırköy Dr. Sadi Konuk Training and Research Hospital, Clinic of Pediatrics, İstanbul, Turkey
}

Cite this article as: Bülbül A, Bülbül L, Zübarioğlu U, Ocak S, Uslu S. The Comparison of the Management Models for Identifying the Risk of Serious Bacterial Infection in Newborn Infants with a Newly Developed Scale. JAREM 2020;10(1): 70-4

\begin{abstract}
Objective: We aimed to evaluate the major approach protocols of fever in febrile newborn and to define the incidence of serious bacterial infections (SBI) in febrile newborns.

Methods: This study was designed as a prospective observational cohort study and directed between January 2011 and December 2015 . All newborns with a rectal temperature of $z 38^{\circ} \mathrm{C}$ and admitted to the neonatal intensive care unit were eligible for participation in the study. Infants were evaluated and classified as low-risk using the Boston criteria, the Philadelphia criteria, and the Rochester criteria, and our newly developed İstanbul criteria. The protocol results were compared regarding calculations of sensitivity, specificity, negative predictive value (NPV), positive predictive value (PPV), and likelihood ratio (LR).

Results: During the study period, 328 infants were enrolled and the frequency of SBI was found as $38.4 \%$. The leading etiology was fever of unknown origin with $43.6 \%$, followed by urinary tract infection, dehydration, and bacteremia, accounting for $15.5 \%, 14 \%$, and $5.8 \%$, respectively. The highest sensitivity and NPV and the lowest negative LR were noted with the İstanbul protocol. The highest PPV was found in the Philadelphia and Boston protocols.

Conclusion: The low-risk criteria of febrile infant protocols are not sufficiently reliable to exclude the presence of SBI in febrile neonates. The low-risk criteria in our new protocol were detected to be more reliable and may be useful in excluding SBI in the neonatal period.
\end{abstract}

Keywords: Fever, newborn, management, serious bacterial infections, dehydration, bacteremia

\section{INTRODUCTION}

Febrile neonates are at higher risk of serious bacterial infections (SBI). They often need to undergo extensive laboratory investigations and to be hospitalized because if a SBI in a neonate is not diagnosed and treated promptly, it may lead to undesirable consequences. However, the origin of fever in some cases is not infection or other serious diseases, and routine hospitalization or antibiotic treatment are not essential in all neonates. Additionally, iatrogenic complications and emotional stress in parents may increase due to the hospitalization of the infants (1). The widely accepted approach is to determine babies at high risk for SBI and hospitalization, who need intravenous antibiotic treatment, and babies at low risk for $\mathrm{SBI}$, who require treatment on an outpatient basis with or without antibiotics (2-4).

Different approaches for the determination of low-risk neonates

ORCID IDs of the authors: A.B. 0000-0002-3510-3056; L.B. 0000-0002-9201-8907; U.Z. 0000-0001-6053-7043; S.O. 0000-0002-6694-6160;

S.U. 0000-0002-2004-0419. 
(e.g., anencephaly, truncus arteriosus), admission to pediatric surgery, antibiotic use before hospitalization, and insufficient records were accepted as exclusion criteria.

\section{Patients Data}

The following data were collected from all babies included in the study: The demographic features (birth weight, age and gender), general evaluation (appearing good and ill), medical history, physical examination signs, laboratory analysis results, and exact diagnosis. All patients underwent laboratory examinations containing: blood count, CRP, serum chemistry and blood culture, urine analysis and urine culture (obtained by bladder catheterization). Lumbar puncture and cerebrospinal fluid assessment were performed in the presence of neurological signs. If there was evidence of respiratory tract infection, X-Ray was performed.

\section{Definition of Serious Bacterial Infections}

The SBI acceptance criteria were as follows: Firstly, the growth of a known pathogenic bacteria in cultures [bacteremia, meningitis, pneumonia and urinary tract infection (UTI)] and secondly any disease that is often associated with bacterial pathogens such as abscess, mastitis, omphalitis, acute otitis media and cellulitis. The diagnosis of pneumonia was made according to the lung X-Ray findings presented by the radiologist.

All samples were assessed using standard microbiological methods to culture. The sample was not processed for viral cultures. If the organism is known to cause disease in neonate, blood culture isolates are accepted to be pathogenic. The isolation of a single pathogen by catheterization with $>10^{4}$ colony-forming units $/ \mathrm{mL}$ in urine was considered UTI. Leukocyte $\geq 10$ cells $/ \mathrm{mm}^{3}$ in uncentrifuged urine or with the dipstick stripe a positive result for nitrite or leucocyte esterase was defined as positive urine analysis.

Viral agent evaluation methods: Newborn with respiratory signs such as runny nose, sneezing or coughing were assessed from nasopharyngeal secretions by influenza-Ag (immunoassay test produced by Dalian Rongbang Medical Healthy Devices, Spain) and respiratory syncytial virus antigen: Rapid immunochromatographic test produced by Prima lab SA, Switzerland).

Definition of dehydration: All neonates were weighed at admission and weight loss was assessed according to the birth weight. Dehydration is defined as the weight loss more than twelve percent with a serum sodium level $\geq 145 \mathrm{mEq} / \mathrm{L}$.

Our newly proposed protocol (İstanbul) includes: (1) Unremarkable medical history (no perinatal antibiotic use, no chronic disease, no hospitalization longer than the mother); (2) good appearance (unremarkable physical examination); (3) no focal physical signs of infection; (4) CRP level $<1 \mathrm{mg} / \mathrm{dL}$; (5) white blood cell count $5000-15.000 / \mathrm{mm}^{3}$ and immature/total neutrophil ratio $(\mathrm{I} / \mathrm{T})<0.2$; and $(6)$ normal urine analysis.

Infants who met these criteria were considered to be at low risk for SBI. All infants were classified as low risk using the criteria of the Rochester, Boston, Philadelphia and Istanbul protocols. The criteria of the four protocols are presented in Table 1. Our anomaly, the presence of a chronic illness, congenital anomaly 
newly created protocol is different because of its inclusion of only febrile newborns, the addition of CRP levels in the laboratory examination, and with defined dehydration in febrile newborn features (Table 1).

\section{Statistical Analysis}

Statistical analysis was performed with SPSS version 16.0 (SPSS, Chicago, IL, USA). Categorical variables are given in percentages with mean \pm standard deviation. The positive predictive value (PPV), NPV, and likelihood ratio (LR) for SBI of the low-risk criteria were calculated using the standard statistical formula. All patients were evaluated according to the Boston, Philadelphia, Rochester, and İstanbul protocols, and the results were compared for sensitivity, specificity, NPV, PPV, and accuracy values for predicting SBI. Statistical significance was accepted as $p<0.05$.

\section{RESULTS}

In the study period, 412 febrile newborns aged $\leq 28$ days, who were hospitalized due to fever, were evaluated. The flow diagram of study is presented in Figure 1. A total of 328 infants fulfilled the inclusion criteria of the study. Of 328 infants in the study, 184 (56.1\%) were boys. The mean birth weight was $3214 \pm 492$ gram, gestational age was $39.2 \pm 1.4$ weeks, mean rectal temperature was
38.3 $\pm 0.4{ }^{\circ} \mathrm{C}$ (lower and upper limit: $38-40{ }^{\circ} \mathrm{C}$ ), and the mean age during admission to the hospital was $12.5 \pm 8.0$ days (lower and upper limit 1-28 days). The ratio of SBI was found to be $38.4 \%$ during the study period.

Febrile illness with no detectable cause was the most common diagnosis which accounted for $43.6 \%$ of all cases. UTI (15.5\%), dehydration (14\%), bacteremia (5.8\%) pneumonia (5.5\%), viral respiratory tract infection (4.0\%), and meningitis (3.7\%) were the next most common diagnoses.

The comparison of sensitivity, specificity, PPV, NPV, and LR for the four protocols is presented in Table 2. The highest sensitivity and NPV and the lowest LR (-) were observed in İstanbul protocol, whereas high specificity and the highest LR (+) were detected in the Boston protocol. The highest PPV was found in the Philadelphia and Boston protocols (Table 2).

\section{DISCUSSION}

In current protocols for the evaluation of fever in infants aged $\leq 3$ months, if no risk of severe bacterial infection is determined, infants can be observed without admission with close examination and monitoring. However, this approach is widely deemed as unacceptable in the neonatal period. The main purpose of our

\begin{tabular}{|c|c|c|c|c|}
\hline & Boston $^{(6)}$ & Philadelphia ${ }^{(11)}$ & Rochester ${ }^{(8)}$ & İstanbul \\
\hline Study design & Prospective & Prospective & Prospective & Prospective \\
\hline Patient group & 28-89 days & $29-60$ days & $\leq 60$ days & $\leq 28$ days \\
\hline \multicolumn{5}{|l|}{ Criteria } \\
\hline History & $\begin{array}{l}\text { No immunization within } \\
\text { last } 48 \text { hours, } \\
\text { No antimicrobial given } \\
\text { within } 48 \text { hours }\end{array}$ & Not defined & $\begin{array}{l}\text { No perinatal antibiotics, } \\
\text { No underlying disease, } \\
\text { Not hospitalized longer } \\
\text { than the mother }\end{array}$ & $\begin{array}{l}\text { No perinatal antibiotics, } \\
\text { No underlying disease, } \\
\text { Not hospitalized longer } \\
\text { than the mother }\end{array}$ \\
\hline $\begin{array}{l}\text { Well appearance with unremarkable } \\
\text { physical examination and absence of } \\
\text { any local infection }\end{array}$ & + & + & + & + \\
\hline Healthy before & + & Not defined & + & + \\
\hline Absence of dehydration & + & Not defined & Not defined & + \\
\hline Leucocyte count, cells $/ \mathrm{mm}^{3}$ & $<20.000$ & $<15.000$ & $5.000-15.000$ & $5.000-15.000$ \\
\hline Band/neutrophil ratio (I/T) & Not defined & $<0.2$ & $A B C \leq 1.500$ & $<0.2$ \\
\hline Urine analysis, WBC/hpf & $<10$ & $<10$ & $\leq 10$ & $<10$ \\
\hline CSF, leucocyte, cells $/ \mathrm{mm}^{3}$ & $<10$ & $<8$ & Not defined & $<10$ \\
\hline Chest radiography & $\begin{array}{l}\text { No infiltration (if } \\
\text { obtained) }\end{array}$ & No infiltration & $\begin{array}{l}\text { No focal infiltration (if } \\
\text { clinically indicated) }\end{array}$ & $\begin{array}{l}\text { No infiltration (if } \\
\text { clinically indicated) }\end{array}$ \\
\hline Stool examination & Not defined & $\begin{array}{l}\text { No blood or } \\
\text { leucocyte } \\
\text { (if indicated) }\end{array}$ & $\begin{array}{l}\leq 5 \text { leucocyte (if } \\
\text { indicated) }\end{array}$ & $\begin{array}{l}<5 \text { leucocyte (if } \\
\text { indicated) }\end{array}$ \\
\hline
\end{tabular}


study was to investigate whether these protocols were suitable for monitoring febrile newborn infants.

The management of febrile illnesses in babies aged $<90$ days vary considerably among physicians. The reason for this variation is associated with the wide range of management protocols suggested during the last few decades $(6-8,11)$. The current suggestions for the assessment and management of young febrile infants are based on studies conducted in the late 1980s and early 1990s (12). The globally accepted approach is to determine infants at high risk for $\mathrm{SBI}$ and in need of hospitalization for intravenous antibiotic treatment, and also to determine infants at low risk, who can safely go through outpatient care with or without antibiotics therapy (4). Three main studies reported the efficacy and safety of outpatient management of febrile infants considered at low risk for SBI $(6,8,11)$. The rate of newborn infants in these three studies was $10-15 \%$ of all infants, which is very low. In a comprehensive review on SBI identification in infants younger than 90 days, it was stated that the Boston and Philadelphia protocols were more accurate when applied to older infants rather than neonates. The

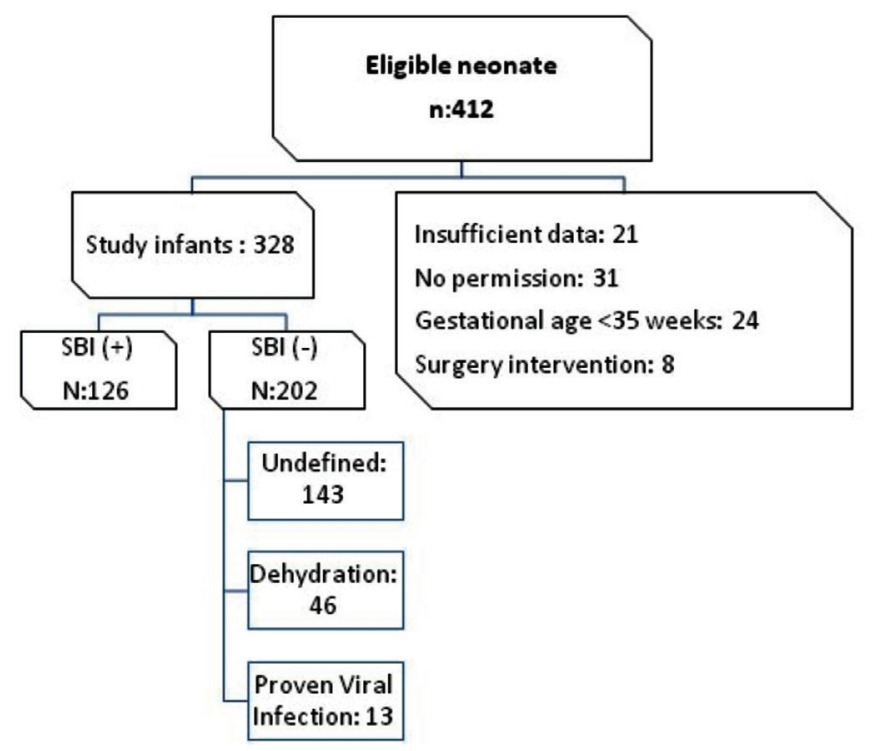

Figure 1. Flow diagram of the study $\mathrm{SBI}$ : Serious bacterial infections
Rochester protocol, on the other hand, was more accurate for neonates than older infants (12).

The management and treatment of newborns with fever vary widely among centers (13). These differences indicate the need of national or international guidelines for the evaluation of fever in neonatal period. Accordingly, given that the prevalence of SBI is higher in neonatal period, generally accepted practice in most centers is a full sepsis evaluation and hospitalization (14).

The prevalence of SBI in infants less than 3 months with fever is about $7.1-19.7 \%$. The prevalence of $\mathrm{SBI}$ is higher in neonatal period (9-28\%) than in infants aged 2-3 months (7.1\%) (15-21). Garcia et al. (17) reported SBI prevalence as $31.9 \%, 33.3 \%$, and $18.3 \%$ in infants aged 7-14 days, 15-21 days, and $>21$ days, respectively. In our study the incidence of SBI was high and our findings supported that $\mathrm{SBI}$ was seen more frequently in the newborn babies.

Several protocols that bring clinical and laboratory criteria together to diagnose young infants ( $<90$ days of life) at low risk for SBI, who can be safely managed as outpatients, have been published. The use of these protocols are advised for different age groups of infants (Philadelphia: 29-60 days; Rochester: 60 days or younger; Boston: $28-89$ days) $(6,8,11)$. Our protocol was designed to be used only in newborn (0-28 days) babies. The main aim of our study was to evaluate febrile newborns in their first month of life according to these protocols. When evaluated separately, the neonates did not show similar test characteristics with older children or the whole group aged $<3$ months. The combined laboratory and clinical parameters demonstrated lower sensitivity in neonates as compared to older groups. Likewise, the falsepositive rate for SBI tended to be higher in neonates compared to older infants (12). The comparison of different diagnostic tests across the age groups ( $\leq 28$ days vs $>29$ days) was possible only for a few selected criteria reported in 14 studies. The Boston criteria and Philadelphia protocol have shown higher sensitivity, lower specificity, smaller PPV, and similar NPV when applied to older infants (age >28 days) compared to newborn babies for overall $\mathrm{SBI}$ or bacteremia. Contrarily, the Rochester criteria were more accurate (higher sensitivity, specificity, and PPV) in neonates than in older infants for SBI or bacteremia. The false positive ratio for $\mathrm{SBI}$ (i.e., the percentage of infants with $\mathrm{SBI}$ classified as low risk) tended to be higher for neonates (1.0\% to 6.25\%) versus older infants (0\% to $5.4 \%$ ) (12).

\begin{tabular}{|c|c|c|c|c|c|c|c|}
\hline Protocols & $\begin{array}{l}\text { Sensitivity } \\
(95 \% \mathrm{Cl})\end{array}$ & $\begin{array}{l}\text { Specificity } \\
(95 \% \mathrm{Cl})\end{array}$ & $\begin{array}{l}\text { PPV } \\
(95 \% \mathrm{Cl})\end{array}$ & $\begin{array}{l}\text { NPV } \\
(95 \% \mathrm{Cl})\end{array}$ & $\begin{array}{l}\text { Accuracy } \\
(95 \% \mathrm{Cl})\end{array}$ & LR (+) & $\operatorname{LR}(-)$ \\
\hline Boston & $\begin{array}{l}61.6 \% \\
(54-68.7)\end{array}$ & $\begin{array}{l}81.7 \% \\
(75.1-86.9)\end{array}$ & $\begin{array}{l}77.1 \% \\
(69.2-83.5)\end{array}$ & $\begin{array}{l}68 \% \\
(61.2-74.1)\end{array}$ & $\begin{array}{l}71.7 \% \\
(66.5-76.3)\end{array}$ & 3.37 & 0.47 \\
\hline Rochester & $\begin{array}{l}47.6 \% \\
(40.1-55.2)\end{array}$ & $\begin{array}{l}72 \% \\
(64.6-78.3)\end{array}$ & $\begin{array}{l}62.9 \% \\
(54.1-70.9)\end{array}$ & $\begin{array}{l}57.8 \% \\
(51-64.4)\end{array}$ & $\begin{array}{l}59.8 \% \\
(54.4-64.9)\end{array}$ & 1.70 & 0.73 \\
\hline Philadelphia & $\begin{array}{l}67.7 \% \\
(60.2-74.4)\end{array}$ & $\begin{array}{l}79.9 \% \\
(73.1-85.3)\end{array}$ & $\begin{array}{l}77.1 \% \\
(69.6-83.2)\end{array}$ & $\begin{array}{l}71.2 \% \\
(64.3-77.3)\end{array}$ & $\begin{array}{l}73.8 \% \\
(68.8-78.2)\end{array}$ & 3.36 & 0.41 \\
\hline İstanbul & $\begin{array}{l}81.7 \% \\
(75.1-86.9)\end{array}$ & $\begin{array}{l}56.1 \% \\
(48.4-63.5)\end{array}$ & $\begin{array}{l}65 \% \\
(58.3-71.2)\end{array}$ & $\begin{array}{l}75.4 \% \\
(67.1-82.2)\end{array}$ & $\begin{array}{l}68.9 \% \\
(63.7-73.7)\end{array}$ & 1.87 & 0.33 \\
\hline
\end{tabular}




\section{Study Limitations}

This study has some limitations. The study included only febrile neonates but many more neonates presented with or developed $\mathrm{SBI}$ without fever. Neonates with non-febrile sepsis were not included in the study. Further studies with larger patient series are needed to validate our new protocol.

\section{CONCLUSION}

In this prospective observational study, we performed a comparison of the results of four protocols (Rochester, Philadelphia, Boston and İstanbul) in 328 febrile neonates. Our study demonstrated that the incidence of SBI in febrile newborns was encountered with higher rates. The most common etiology was UTI in neonates with SBI. The low-risk criteria of the Rochester, Philadelphia, and Boston protocols are not sufficiently reliable to exclude the presence of $\mathrm{SBI}$ in febrile neonates. In our study, with the inclusion of CRP, NPV was found at the highest level. The low-risk criteria in our newly created protocol were detected as more reliable and may be useful for excluding SBI in the neonatal period.

Ethics Committee Approval: The study protocol was approved by : Şişli Etfal Training and Research Hospital Ethics Committee (approval number: 745-2011).

Informed Consent: Written informed consent was obtained from the parents.

Peer-review: Externally peer-reviewed.

Author Contributions: Concept - A.B., L.B., U.Z., S.O., S.U.; Design - A.B., L.B., U.Z., S.O., S.U.; Supervision - A.B., L.B., U.Z., S.O., S.U.; Resource A.B.; Materials - S.O., U.Z.; Data Collection and/or Processing - L.B., U.Z.; Analysis and/ or Interpretation - L.B., A.B.; Literature Search - S.O., L.B.; Writing Manuscript - L.B.; A.B., S.O.; Critical Reviews - L.B.

Conflict of Interest: The authors have no conflict of interest to declare.

Financial Disclosure: The authors declared that this study has received no financial support.

\section{REFERENCES}

1. Marom R, Sakran W, Antonelli J, Horovitz Y, Zarfin Y, Koren A, et al. Quick identification of febrile neonates with low risk for serious bacterial infection: an observational study. Arch Dis Child Fetal Neonatal Ed 2007; 92: 15-8.

2. Nosrati A, Ben Tov A, Reif S. Diagnostic markers of serious bacterial infections in febrile infants younger than 90 days old. Pediatr Int 2014; 56: 47-52.

3. Baker MD, Bell LM, Avner JR. The efficacy of routine outpatient management without antibiotics of fever in selected infants. Pediatrics 1999; 103: 627-31.
4. Rehm KP. Fever in infants and children. Curr Opin Pediatr 2001; 13: 83-8.

5. McCarthy CA, Powell KR, Jaskiewicz JA, Carbrey CL, Hylton JW, Monroe DJ, et al. Outpatient management of selected infants younger than two months of age evaluated for possible sepsis. Pediatr Infect Dis J 1990; 9: 385-9.

6. Baskin MN, O'Rourke EJ, Fleisher GR. Outpatient treatment of febrile infants 28 to 89 days of age with intramuscular administration of ceftriaxone. J Pediatr 1992; 120: 22-7.

7. Dagan R, Powell KR, Hall CB, Menegus MA. Identification of infants unlikely to have serious bacterial infection although hospitalized for suspected sepsis. J Pediatr 1985; 107: 855-60.

8. Jaskiewicz JA, McCarthy CA, Richardson AC, White KC, Fisher DJ, Dagan $R$, et al. Febrile infants at low risk for serious bacterial infection-an appraisal of the Rochester criteria and implications for management. Febrile Infant Collaborative Study Group. Pediatrics 1994; 94: 390-6.

9. Schwartz S, Raveh D, Toker O, Segal G, Godovitch N, Schlesinger Y. A weekby-week analysis of the low-risk criteria for serious bacterial infection in febrile neonates. Arch Dis Child 2009; 94: 287-92.

10. Bulbul L, Bulbul A, Ocak S, Zubarioglu U, Cengiz M, Uslu S, et al. Etiology and causative pathogens of febrile neonates. Pediatric Infect Dis 2018; 3.

11. Baker MD, Bell LM, Avner JR. Outpatient management without antibiotics of fever in selected infants. N Engl J Med 1993; 329: 1437-41.

12. Hui C, Neto G, Tsertsvadze A, Yazdi F, Tricco AC, Tsouros S, et al. Diagnosis and management of febrile infants (0-3 months). Evid Rep Technol Assess (Full Rep) 2012; 205: 1-297.

13. Jain S, Cheng J, Alpern ER, Thurm C, Schroeder L, Black K, et al. Management of febrile neonates in US pediatric emergency departments. Pediatrics 2014; 133: 187-95.

14. Baraff LJ, Bass JW, Fleisher GR, Klein JO, McCracken GH Jr, Powell KR, et al. Practice guideline for the management of infants and children 0 to 36 months of age with fever without source. Agency for Health Care Policy and Research. Ann Emerg Med1993; 22: 1198-210.

15. Bilavsky E, Yarden-Bilavsky H, Amir J, Ashkenazi S. Should complete blood count be part of the evaluation of febrile infants aged $\leq 2$ months? Acta Paediatr 2010; 99: 1380-4.

16. Baker MD, Bell LM. Unpredictability of serious bacterial illness in febrile infants from birth to 1 month of age. Arch Pediatr Adolesc Med 1999; 153: 508-11.

17. Garcia S, Mintegi S, Gomez B, Barron J, Pinedo M, Barcena N, et al. Is 15 days an appropriate cut-off age for considering serious bacterial infection in the management of febrile infants? Pediatr Infect Dis J 2012; 31: 455-8.

18. Kadish HA, Loveridge B, Tobey J, Bolte RG, Corneli HM. Applying outpatient protocols in febrile infants 1-28 days of age: can the threshold be lowered? Clin Pediatr (Phila) 2000; 39: 81-8.

19. Chiu CH, Lin TY, Bullard MJ. Application of criteria identifying febrile outpatient neonates at low risk for bacterial infections. Pediatr Infect Dis J 1994; 13: 946-9

20. Chiu CH, Lin TY. Application of the Rochester Criteria in febrile neonates. Pediatr Infect Dis J 1998; 17: 267-9.

21. Brown $L$, Shaw $T$, Wittlake WA. Does leucocytosis identify bacterial infections in febrile neonates presenting to the emergency department? Emerg Med J 2005; 22: 256-9. 